\title{
The Study of Corpus as a Tool to Promote the Development of English Teaching
}

\author{
Dapeng WANG \\ Teaching and Research Institute of Foreign Languages \\ Bohai University \\ Jinzhou,Liaoning, 121013 China
}

\begin{abstract}
Foreign practice teaching, carried by corpus, play an important role in fostering applied talents of high level of language skills, elaborated direction and prospects of Corpus building for the practical teaching mode, Corpus teaching practice play an important role in foreign language.
\end{abstract}

Keywords- corpus, English teaching, development

\section{INTRODUCTION}

Corpus Linguistics has great progress in the past two decades, has become an important branch of modern linguistics. Modern corpus contains a large amount of information; the information can be used to set the language of computer processing. It provides a new idea for linguistic research, in recent years, foreign linguistics and language teaching profession are two of the most popular topic of discussion. Its real language data for the study, analyze from a macro point of a lot of language to find the rule of language. Probabilistic methods in language analysis, based on the actual use of the probability of the phenomenon of language to analyze various aspects of the language.

\section{CORPUS AND RELATED CONCEPTS}

\section{A. Corpus building}

in the "College English Curriculum Requirements" released by Ministry of Higher Education, their are three levels of college English teaching, "General requirements, higher demand and higher requirements" established as the standard classification of open corpus, respectively create sub-libraries. Corpus will be used by our students, "New Horizon College English Course" (1-4 copies) and "New College English Course" (1-4 copies), based on an extensive collection of covers from other sources covering listening, speaking, reading, writing and translation capabilities in five areas of corpus. Corpus genres include education, science and technology, trade, health, sports, culture, people, tourism and so on. All corpus will be madeinto electronic text, content formats and convert it into plain text or XML format. And use entry software system of computer technology development corpus to protect the integrity and credibility of the data corpus, and screening, labeling and processing to corpus, and put qualified corpus into the system. Corpus means electronic database through the sampling method based on the collection and naturally occurring according to the purpose and corpus selection method to order the use of language materials. In other countries, the corpus used in language teaching has made some achievements, the corpus construction and development, such as construction starts by the Belgian scholar Professor Grange (ICLE) has now been widely used in academic research, combined corpus with second language acquisition, such as Tim Johns presents a new use of corpus data aided language learning- "data-driven learning."

\section{B. Direction and prospects of corpus building}

When it comes to prospects of the development of the corpus, corpus linguists have multiple ideas. Throughout each direction, the development of corpus will be mainly reflected in the following three aspects. (1) The development of basic corpus. Since the 1990s, due to the importance of the national corpus, many European countries have invested large corpus, such as Oxford University Press launched British National Corpus. This momentum will continue to build the library. because the large corpus of work marked lag in the coming period, we should also focus on the development of small dedicated corpus, in addition, the development of spoken language corpus should intensify its efforts to overcome the current imbalance in written and spoken corpus development, to promote the development of spoken language research. (2) The development of the corpus annotation. Corpus annotation is the basis for the analysis of multi-dimensional language, but such an analysis is not limited to those of the original label, and thus the effective use of corpus is largely dependent on the level and quality. Currently the development of language at all levels is uneven, there is rapid development in vocabulary, syntactic, voice and phoneme, the future should focus on strengthening the labeling semantic layer and pragmatic layer.

\section{The development of corpus processing tools}

As a unique and powerful technology tools, computer makes this new linguistic possible. With the in-depth study of English corpus linguistics, researchers have developed many corpus analysis and application software, such as OCP, TACT, Word Cruncher and Word Smith and so on. However, software development do not broke the portal of the points, do not promote the use of corpus, software of corpus analysis developed rapidly with less application of software. 
Corpus analysis and the application and development of software have major significance and broad prospect.

\section{THE DEVELOPMENT STATUS OF CORPUS}

Specific research areas tend to wide, but with unevenly distributed. Corpus application in the field of English teaching has begun to verify beyond a certain word or phrase level. Its research has become increasingly diversified into almost every aspect of English teaching. As we can see from the statistical classification thesis, currently the contents of the corpus applied to English teaching institute has involved teaching vocabulary, grammar teaching, spelling teaching, writing and translation teaching, oral teaching, discourse and discourse studies. These studies can provide richer teaching resources and convenient system for majority of English teachers, can take full advantage of these resources which contribute to updating the entire education system, and greatly advance the pace of English teaching reform. It also should be noted that, although the content of teaching and research in the field of corpus was broaden with uneven distribution. Vocabulary teaching occupies a large proportion. its relative research involves collocation research, to define the type of college English vocabulary and complex formula, the acquisition of non-Chinese students in English class of the use of the definite article, the corpus and vocabulary, academic vocabulary and the development characteristics of productive vocabulary, deriving affix analysis of English vocabulary repeating pattern, characterized by the development of speech coupled, high frequency verbs, articles acquisition, English vocabulary teaching class connection, collocation, and chunk, spoken word essay in English studies, English synonyms distinguish explore research papers in English and other directives. Thus, vocabulary teaching is an area with the largest corpus research and resources and research results used in English teaching.

\section{THE PRACTICAL TEACHING MODE CARRIED BY CORPUS}

the practical teaching mode carried by corpus is studentcentered, under the guidance of teachers with corpus as carrier, taking advantage of retrieval and statistical functions to analyze and summarize the rules and characteristics of a true language in different contexts, and in the teaching model applied to the study and practice of imitation. Students use retrieval and statistical functions to analyze real corpus of foreign language to grasp the rules of the language. Students can use the following three kinds of corpus retrieval and statistics: (1) the frequency analysis of lexical items, to arrange all the words in the corpus alphabetically or by frequency of occurrence according to the length of the word table. (2) Context of the co-occurrence analysis, before and after the context of a word or phrase in the form of the first appearance in the entire corpus of each list, and you can set the length of the context of the extension of the front and rear if it is needed. (3) Make statistical analysis of the project on their own, for example, when students learn to speak English conversation synchronous communication, they check out a series of synchronized retrieve instances of discourse in the corpus, and show their language ecology. In the teaching process, students observe and analyze the real context of the language, the language law and the establishment of language summary mode, and finally get to practical application. These three aspects are bonded in a chain, ad infinitum, and spiraling trend, and ultimately speak the same as the tribe and appropriately use foreign language.

\section{TO PROMOTE THE DEVELOPMENT OF ENGLISH TEACHING}

\section{A. Corpus can promote college English writing}

Corpus is able to solve the problem of limited student's information input and it provides a lot of valuable input, which can also enhance students' awareness of body language. Teachers can make use of this huge corpus repository for teaching services. According to the actual needs of teaching, teachers can select from pre-Corpus associated with teaching, and genre diversity and representation of material as teaching aid to explain the information to the students, so that students can master discourse features in the learning process, it can greatly improve their writing skills. On the other hand, due to the different vocabulary and grammatical structures appear in different frequency, corpus can analyze type, frequency, sentence length, sentence complexity and other aspects of vocabulary, the representative body language material presented to the learner can help them in learning detours.

Corpus learners can analyze the error that appears in writing, to improve the learners' language awareness in writing. As an adjunct to the computer, learners use corpus to overcome this problem, the learner corpus refers to the frequency of the learner can get a variety of errors that appear in writing retrieved by a computer, teachers can always put their students' writing, diary or exercise to gather together to create a learner corpus, it is stored in the computer as text documents. In this way, teachers can master types of error distributions, and can learn from the mistakes of the frequency of making mistakes, can understand exactly what the error occurs in writing, why make such a mistake, etc., then, they can targeted to teach, in addition, learners can self-discover to find the right language form.

\section{B. Teaching Test Specification}

There is an interdependent relationship between language teaching and language tests, teaching effectiveness can be tested by the test, and feedback we get from detection also helps to improve and enhance the quality of teaching, or to improve the curriculum. In English teaching, corpus linguistics can be applied to the proposition, paper analysis and design language and other aspects of the test pattern. In proposition, corpus can help the proposition find out the title material easily. More importantly, the proposition can determine the language test based on frequency information and error analysis corpus. According to statistical analysis of data carried proposition corpus, we can effectively improve 
the reliability and validity of the test for scientific examination and targeted to provide an effective guarantee. Enrich the teaching content, on one hand, make use of modern information technology building a parallel corpus, multi-modal corpus, dynamic corpus, etc., it can provide support for the teaching of basic data; you can achieve virtual corpus-driven learning, so that learning English become easier, enjoyable and efficient. On the other hand, it can provide for English language teaching frequency information, contextual information, grammatical information and pragmatic information to improve the description of the language, and lay a solid foundation for the development of pedagogy.

\section{Through the use of vocabulary research to improve the ability of students to use vocabulary}

Undoubtedly, for foreign language learners, it is more important to learn usage of words than just know the dictionary definition. However, in traditional teaching, we usually only required to master the meaning of words, in other words, as long as we make mistaken in understanding of the meaning of a word, it is enough to express what is it in a different sentence. This has resulted in extreme imbalance between input and output, that is, even if they have learned a lot, but it is difficult to apply their knowledge. The result is a serious gap between learning and application. The corpus is based on Discrimination and word synonyms with research; you can improve students' ability to use words.

In English teaching and research, corpus linguistics and corpus has been playing a very important role, it has a significant impact in terms of theory, contents and methods of language teaching and research, such as the teaching of English, and classical dictionary and grammar book which is written in English on the basis of the corpus. Corpus applications extend from traditional areas to emerging areas, corpus-based research methods will gradually be taken seriously and widely used English Corpus and Corpus Linguistics will play a greater role in the future of English teaching and research. For the study of vocabulary, grammar school, language theory, history, linguistics, the role of the corpus, mostly through the corpus retrieval and frequency statistics, help people observe and grasp the language facts, analysis and study of language laws. Developing corpus approach will play a supporting role in changing application to necessary resources and tools. Using Corpus, one can specify the syntax to quantify the phenomenon, and testing and verify language theory, rules or assumptions.
Corpus is a huge collection of language material, mainly used for a variety of features to observe, analyze and research the target language. It provides a wide range of language materials and information such as word formation, matching information, contextual information quickly and accurately. Vocabulary has the most outcomes and appears the earliest in the field of foreign language teaching.

\section{CONCLUSIONS}

In summary, corpus, based on web technology to create college English teaching platform, allows a certain degree of English teaching and learning to get rid of restrictions of time and place, and it also play an important role in irretrievability, development, resources, autonomy and research and other characteristics in corpus technology in teaching and learning process. It provides different possibilities for teachers implementing individualized instruction with providing personalized, interesting learning tool for students, so that students can self-study according to their ability and time to improve their English language proficiency.

\section{REFERENCES}

[1] Xi Lu Ting, Wu Lixi. Corpus action in college English education Taking New Universities example [J] Chongqing Three Gorges University,2011,05:152-154.

[2] Song Yunxia, Zhang Dawei, SUN Zhuo. Weijun. Research Practice teaching mode corpus as the carrier[J].. Experimental Technology and Management,2011,09:110-113.

[3] Xie Yuanhua. Based on Vocabulary and Language Teaching Corpus [J]. Guangdong University of Foreign Studies, 2002,02:6-12.

[4] Wu Fei. Domestic and foreign construction and development of English Corpus Review [J]. Shandong Foreign Language Teaching,2007,06:28 -31+65.

[5] Shi Liang. Corpus application and development at the University of Foreign Language Teaching [J]. Modern Enterprise Education,2013,14:226-227.

[6] Huang Ping, YAN Chao Ya. English teaching and research applied to the domestic status of the corpus $[\mathrm{J}]$. Shandong Foreign Language Teaching,2010,05:44-50.

[7] Zhang Rui, Zhou Haiyan. Corpus application in college English classroom teaching[J]. Changchun University of Technology (Higher Education Study Edition),2009,03:81-82.

[8] Wang san. English corpus linguistics development in China [J]. Shanxi Normal University (Social Science Edition), 2007, S1 :122123. 